\title{
The necessity of a holistic approach when managing marine mammal-fisheries interactions: Environment and fisheries impact are stronger than seal predation
}

\author{
David Costalago (D), Barbara Bauer, Maciej T. Tomczak, Karl Lundström, \\ Monika Winder
}

Received: 29 January 2018/Revised: 7 July 2018/Accepted: 13 November 2018/Published online: 8 December 2018

\begin{abstract}
Seal populations are recovering in many regions around the world and, consequently, they are increasingly interacting with fisheries. We used an Ecopath with Ecosim model for the offshore Central Baltic Sea to investigate the interactions between the changes in fish stocks and grey seal (Halichoerus grypus) population under different fishing and environmental scenarios for the twenty-first century. The assumed climate, eutrophication and cod (Gadus morhua) fisheries scenarios modified seal predation impacts on fish. Fish biomass and catches are more affected by fishing mortality and the environment than by seal predation. Our results highlight that the impacts of the increasing seal population on lower trophic levels are complex; thus, we emphasize the need to consider a range of possible ecosystem contexts when evaluating potential impacts of top predators. Finally, we suggest that an increasing seal population is not likely to hinder the preservation of the main Baltic fish stocks.
\end{abstract}

Keywords Atlantic cod Atlantic herring - EwE . Fisheries management - Marine mammals · Sprat

\section{INTRODUCTION}

During the second half of the twentieth century, conservation efforts led to the improvement of the status of numerous marine mammal populations worldwide (Lotze et al. 2011; Magera et al. 2013; Chasco et al. 2017). Many marine mammal species feed mostly on fish, which consequently leads to a polarized discussion regarding the

Electronic supplementary material The online version of this article (https://doi.org/10.1007/s13280-018-1131-y) contains supplementary material, which is available to authorized users. potential effects of these animals on fish catches. For example, $80 \%$ of all seal species worldwide, including phocids (true seals), otarids (eared seals) and walrus, have been recorded to have some form of negative effect on fishing or fish farm operations (Wickens 1995; Trzcinski et al. 2006). However, in many cases, the conflicts between piscivorous predators and fishery arise from poor understanding of the system's complexity of predator-prey interactions and lack of consideration of other pressures affecting the food web.

Many studies quantify the losses to fishery without taking into account that (1) not every fish is caught, even if predators are lacking (Yodzis 2001; Heikinheimo et al. 2016), and (2) there might be several confounding factors shaping the seals' potential for predation (e.g. climate change, competitors and diseases (O'Boyle and Sinclair 2012; Morissette and Brodie 2014). Thus, estimating the seals' trophic impact on their prey populations is challenging but important to evaluate the extent of the topdown control by seals. In addition, marine ecosystems are being rapidly altered by climate change, fishing activities and eutrophication, among other factors. It is thus necessary to develop tools that allow us to understand and to predict the effects of a changing environment on marine mammals and the interactions between their populations and fish stocks. This understanding can inform the debate on the conservation and management of marine mammals and fisheries and alleviate conflicts.

In the northern hemisphere, the most abundant pinniped species are grey seal Halichoerus grypus, harbour seal Phoca vitulina, harp seal Pagophilus groenlandicus and ringed seal Pusa hispida, although harp and ringed seals are typically arctic species (Perrin et al. 2009). In Europe, seals have been reported to interact with the fisheries in some of the most important fishing grounds, e.g. the North 
Sea (Furness 2006), the Barents Sea (Bogstad et al. 2015) and the Baltic Sea (Varjopuro 2011; Gårdmark et al. 2012). Thus, there is a growing concern regarding the impact that grey seals might have on some of the most important fish stocks in the region, e.g. Eastern Baltic cod (Gadus morhua) and Atlantic herring (Clupea harengus). For the Baltic Sea, the exponential increase of the grey seal population since the 1980s raised concerns in the fisheries sector (Lundström et al. 2010; Varjopuro 2011). This region experienced, in addition, vast impacts of climate change and eutrophication (MacKenzie et al. 2012; Niiranen et al. 2013; Meier et al. 2014; Elmgren et al. 2015), which make this region a suitable study case to estimate the extent to which the increasing number of seals interact with fisheries under different environmental scenarios.

Here, we used the Baltic Proper (Fig. 1) as a model to investigate the role of grey seals in a system highly affected by multiple human pressures. We aimed at quantifying the contribution of grey seal predation on the most economically important fish stocks in the Baltic Sea (i.e. Eastern Baltic cod, Baltic herring and sprat (Sprattus sprattus)) under different future environmental conditions. Ultimately, we aim at providing new insights for management and conservation from an ecosystem perspective, and to aid at resolving conflicts where fisheries and seals interact.

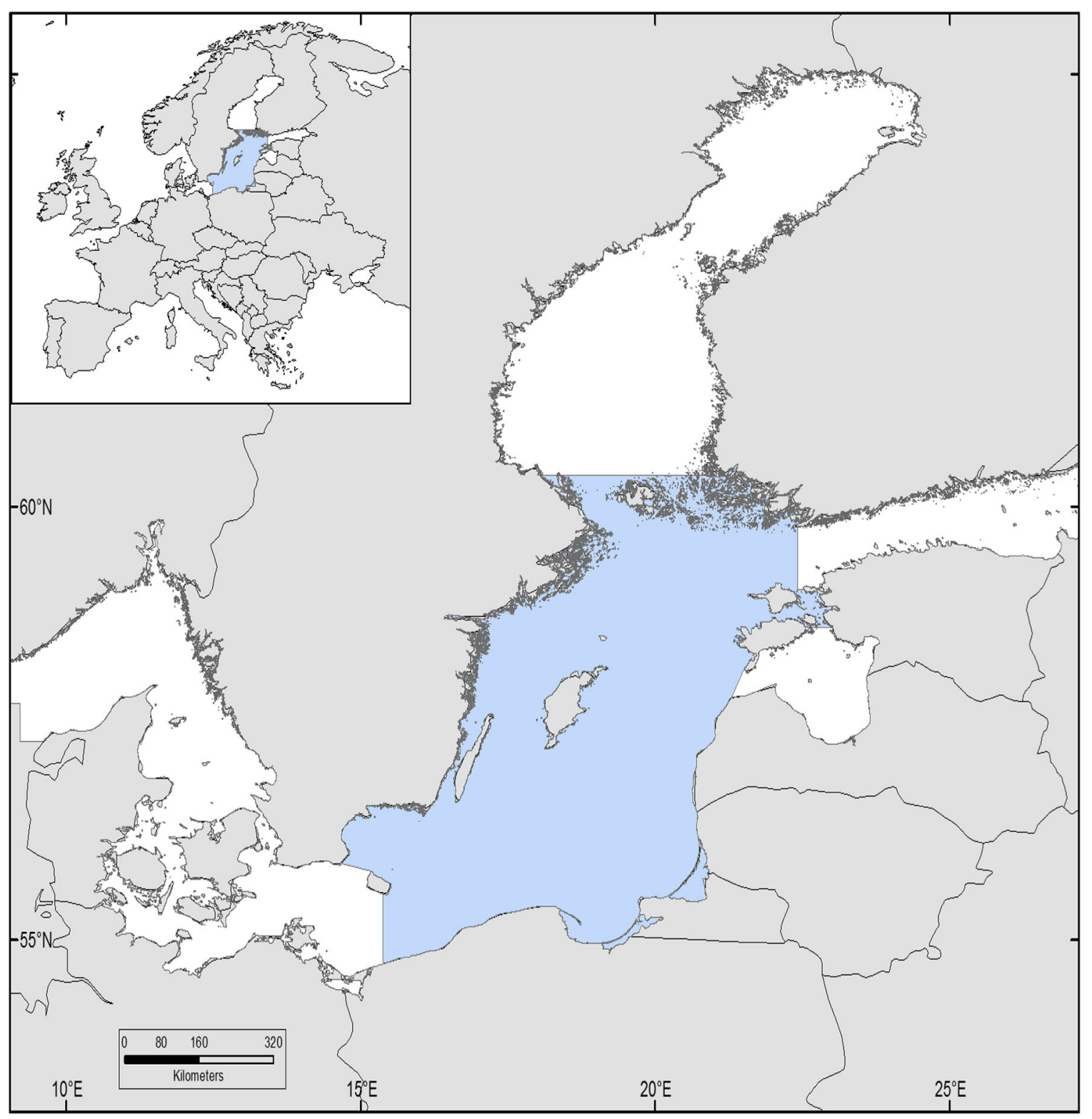

Fig. 1 The Baltic Proper study area (blue) includes the ICES subdivisions 25-27, 28-2 and 29 


\section{MATERIALS AND METHODS}

\section{Study area}

The Baltic Sea is one of the world's largest brackish water bodies. This area hosts four resident species of marine mammals, grey seal being the most abundant of them. The Baltic Proper area covered in the model (Fig. 1) extends approximately $2.4 \times 10^{5} \mathrm{~km}^{2}$. Most Baltic grey seal individuals concentrate in the Baltic Proper (Härkönen et al. 2013) and the largest stocks of Eastern Baltic cod, Baltic herring and Baltic sprat are also found in that area (ICES 2017b). Landings of herring from the pelagic fisheries reached a peak in the mid-1970s. In the late 1980s, a decline in Baltic cod abundances led to a decrease in landings (Casini et al. 2008). The Eastern Baltic cod stock in the Baltic Proper showed weak signs of recovery in the beginning of the twenty-first century (Gårdmark et al. 2015; Raid et al. 2016), whereas the central Baltic herring stock biomass, although currently increasing and above safe biological limits, is still about half the size it was in the 1970s. However, it is uncertain whether these increases will continue (Svedäng and Hornborg 2015). Sprat biomass increased rapidly in the late 1980s-early 1990s, but before the start of the twenty-first century, it decreased to values similar to those in 1970s (Eero 2012).

\section{Ecopath with Ecosim model parameterization}

Ecopath with Ecosim (EwE) is a widely used food-web modelling approach (Christensen and Walters 2004). It consists of Ecopath, a mass-balanced, static model describing trophic flows among functional groups in one year (in this case 1974), and Ecosim, a dynamic simulation model. To estimate the magnitude of the trophic fluxes, an Ecopath model requires input values for parameters such as biomass, diet composition, consumption, fisheries catches and production rates for each functional group (Table S1-S4).

In order to simulate the trophic effects of grey seals on the fish populations as realistically as possible, the existing Baltic Proper Ecopath model (Tomczak et al. 2012, 2013) was updated (Appendix S1). This EwE model was built for the open sea area of the Baltic Proper to describe its food-web dynamics between 1974 and 2006 in order to understand the changes in energy flow and the observed regime shift in the Baltic Sea ecosystem. We assumed that all functional group biomasses were in equilibrium in 1974 (i.e. the 'biomass accumulation' parameter was set to zero for all groups in the Ecopath model) and that there was no significant migration to or from areas outside of the Baltic Proper.

Diet compositions of all functional groups in the model except the seals were kept as described by Tomczak et al. (2012). Briefly, adult and small cod fed primarily on juvenile stages of herring and sprat. A certain degree of cannibalism (6\% of total diet composition) and consumption of prey from outside the system ('import', $8 \%$ of total diet composition) was also accounted for in adult cod. Juvenile cod fed mostly on macrozoobenthos and mysids, and larval cod fed on copepods. Juvenile and adult herring fed mainly on copepods and mysids, and juvenile and adult sprat fed on copepods.

Individual seal consumption was considered to be $6 \mathrm{~kg} \mathrm{day}^{-1}$ for juvenile seals and $6.9 \mathrm{~kg} \mathrm{day}^{-1}$ for adults ( $6 \mathrm{~kg} \mathrm{day}^{-1}$ for females and $7.8 \mathrm{~kg} \mathrm{day}^{-1}$ for males), as estimated by Lundström (2012). Grey seal diets in the Baltic Proper in the periods 1968-1971, 2001-2005 and 2008-2012 were obtained from hunted seals from Söderberg (1975), Lundström et al. (2010) and samples from hunted seals analysed for this study following the methods in Lundström et al. (2010), respectively (Fig. 2). The diet composition in the period 1968-1971 was used as a starting point to parameterize the grey seal diet composition in Ecopath but was modified during the model balancing procedure (see next section).

The Ecosim model has the balanced Ecopath as initial state and simulates how the ecosystem changes compared to that state following one or more forcing factors. Biomass changes in non-age structured groups (all except seals and fish) are modelled as differential equations, based on the Ecosim master equation where biomass change is a function of prey consumed minus losses by predation, fisheries and other mortality. Fish biomasses are modelled by a monthly difference equation system, accounting for changes in population age and size structure in each time step. The model assumes a von Bertalanffy growth curve and weight-dependent fecundity, where weight depends on the amount of prey consumed (Walters et al. 2010). Seal biomass changes are either used as scenario forcing (seal0, seal1 scenarios, Table 2) or modelled similarly to that of fish (seal50, Table 2). Predator diet compositions depend on prey abundances and on the predator preferences ('electivities' in EwE nomenclature) determined in Ecopath (Appendix S1, Fig. S1). After the Ecopath model is balanced, there are still a few additional parameters required by Ecosim (Appendix S2; regarding setting the vulnerability multipliers see text below).

\section{Model balancing and validation}

To ensure that the Ecopath model estimates were balanced and realistic, we used the PREBAL procedure (Link 2010). Additionally, model estimates were analysed by comparing the observed and simulated biomass and catches. We also compared the empirical seal diet data of the three periods, i.e. 1968-1971, 2001-2005 and 2008-2012 with the Ecopath output seal diet obtained from the 'Ecopath from Ecosim' feature for the years 1974, 2001-2005 and 


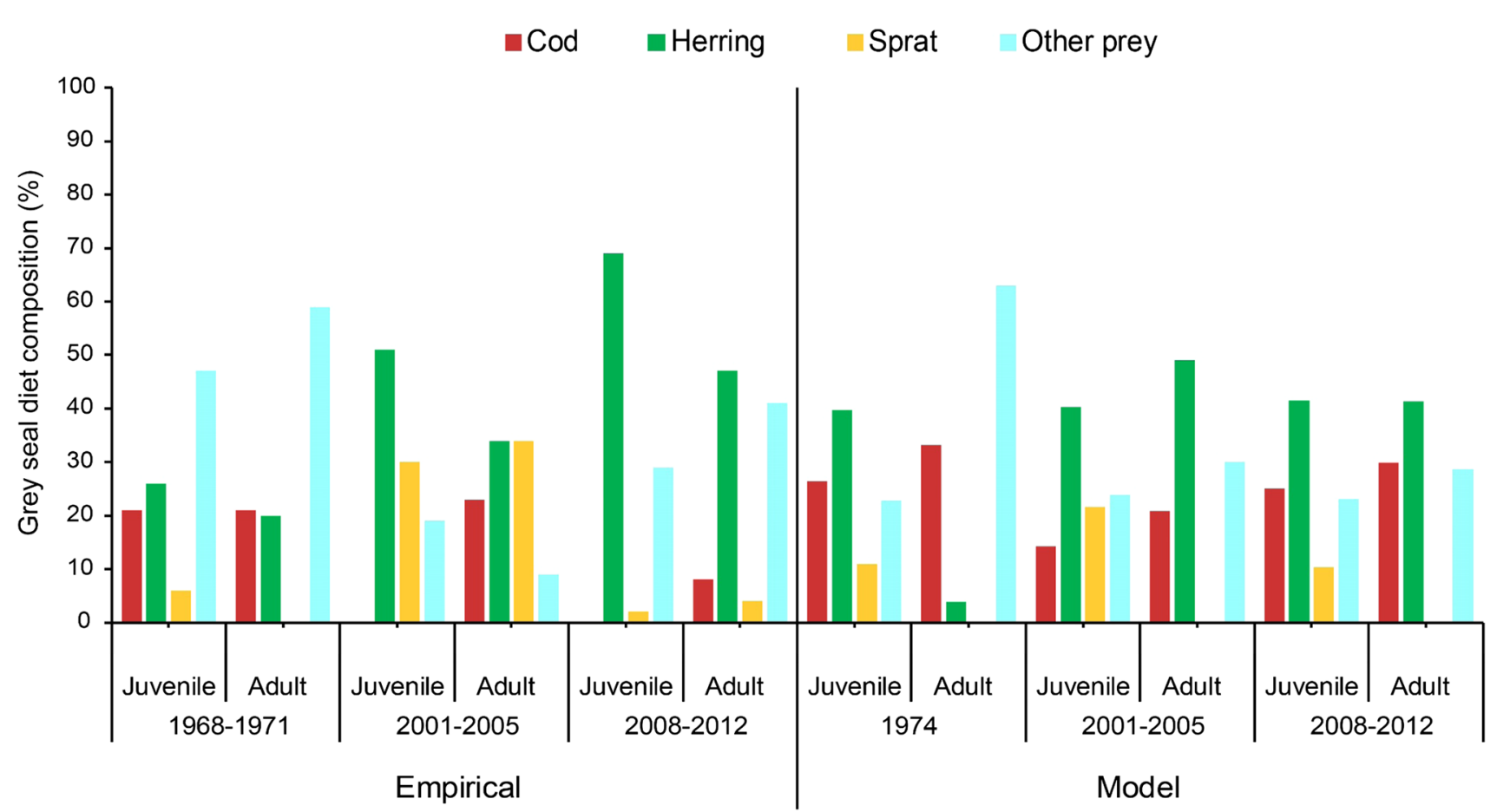

Fig. 2 Composition, in \% biomass, of juvenile and adult grey seal diets in the Baltic Proper according to digestive tract content analyses (left panel) from the periods 1968-1971 (Söderberg 1975), 2001-2005 (Lundström et al. 2010) and 2008-2012 (samples from hunted seals analysed for this study following the methods in Lundström et al. (2010)), and our model grey seal diet outputs (right panel) for 1974, 2001-2005 and $2008-2012$

2008-2012, respectively, to assess whether the diet compositions estimated by the model were realistic.

Subsequently, the Ecosim module was used to create time-dynamic simulations of the food web in response to historical (1974-2015) fishing, environmental and seal biomass forcing. Fishing mortality data for herring and sprat were used as forcing in the model and were obtained from ICES (ICES 2017a) (Fig. S2). The impact of environmental factors (i.e. primary production (PP), sea temperature, salinity, cod reproductive volume and hypoxic area) on the functional groups was modelled using forcing functions (Table 1, Fig. S2, see also Niiranen et al. (2013) and Meier et al. (2014) for details on forcing variables). The environmental variables were chosen based on existing literature on the most important environmental drivers affecting the Baltic Sea food web (Niiranen et al., 2013).

The Ecosim model was calibrated using an automated stepwise fitting procedure that searched for vulnerability multiplier parameters that maximized statistical fit to observed time series (Scott et al. 2015). We used observation data on relative biomasses and catches (1974-2015), obtained from ICES (Tomczak et al. 2012; ICES 2017a) for model calibration. Vulnerability multipliers are also called 'flow control parameters' and are used to limit the biomass flow between a predator and its prey (for more details see Appendix S2).

In addition to adjusting vulnerability multiplier parameters via stepwise fitting, we also adjusted the diet matrix.
In the diet matrix, we reduced the percentage of the import diet by accounting a proportional fraction of it into the different prey groups. The final diet matrix and the 'Electivity' are shown in Table S4 and Fig. S1, respectively. To allow grey seals to switch diet in the model (i.e. to start preferentially consuming a prey that has become more abundant), we assigned the highest possible value (2) to the 'Switching Power' parameter in the Group Info interface for both juvenile and adult seals.

\section{Scenario simulations (2016-2098)}

During the scenario simulations, we varied the same forcing variables (Table 1, Fig. S2) used to force the model in the historical period. Table 2 details the seal abundance, $F_{\text {cod }}$ and environmental scenarios used in the future projections (2016-2098). In the seal0 and seall scenarios, we used seals as 'forcing', i.e. set their biomasses to certain values a priori, excluding bottom-up effects affecting their biomass. In seal50, we forced the seal biomass to grow exponentially, following the current growth trend, until a maximum seal population size of 50 times the initial biomass from 1974, which is past the number of seals that there were in the Baltic Sea in the beginning of the twentieth century [nearly 100000 individuals (Harding and Härkönen 1999)]. This is followed by a stabilization of seal biomass around 2040 of $0.07 \mathrm{t} \mathrm{km}^{-2}$ or 140000 
Table 1 Forcing variables used in the Ecosim model and their respective target group in the EwE model. All environmental forcing variables were applied as anomalies from the Ecopath base year (1974) for the period 1974-2098

\begin{tabular}{|c|c|}
\hline Forcing variable & Target group \\
\hline $\begin{array}{l}\text { Sea surface }(0-10 \mathrm{~m}) \text { temperature } \\
\text { in August; proxy of sprat egg } \\
\text { production }\end{array}$ & Juvenile sprat \\
\hline $\begin{array}{l}\text { Upper water column }(0-50 \mathrm{~m}) \\
\text { temperature in spring }\end{array}$ & Acartia spp., Temora longicornis \\
\hline $\begin{array}{l}\text { Lower water column }(80-100 \mathrm{~m}) \\
\text { salinity, annual average }\end{array}$ & Pseudocalanus acuspes \\
\hline $\begin{array}{l}\text { Phytoplankton production per } \\
\text { biomass (P/B), annual }\end{array}$ & Phytoplankton \\
\hline Hypoxic area, annual average & Macrozoobenthos, mysids \\
\hline $\begin{array}{l}\text { Cod reproductive volume } \\
\text { (volume of water with } \\
\text { salinity }>11 \text { psu and deep } \\
\text { water oxygen } \\
\text { concentration }>2 \mathrm{mg} \mathrm{l}^{-1} \text { ), } \\
\text { annual average; proxy of egg } \\
\text { production }\end{array}$ & Cod larva \\
\hline $\begin{array}{l}\text { Herring recruitment, annual } \\
\text { average biomass of age } 1 \text { class, } \\
\text { proxy of egg production }\end{array}$ & Juvenile herring \\
\hline Seal biomass, annual average & Juvenile seal, Adult seal \\
\hline $\begin{array}{l}\text { Fishing rate }(\mathrm{F}) \text {, defined as yield } \\
\text { per biomass }(\mathrm{Y} / \mathrm{B})\end{array}$ & $\begin{array}{l}\text { Ad. Cod, Small cod, Ad. Herring } \\
\text { Juv. Herring, Ad. Sprat, Juv. } \\
\text { Sprat }\end{array}$ \\
\hline
\end{tabular}

Environmental forcing variables were based on projections from the model BAltic sea Long-Term large-Scale Eutrophication Model (BALTSEM; see (Savchuk et al. 2012a)); fishing mortality forcing and seal biomass forcing were based on observations in the historical period. See Tomczak et al. (2012) and Niiranen et al. (2013) for further details and the data sources of the forcing variables. Forcing function time series (1974-2015) are plotted in Fig. S2

individuals (Fig. S3). The Multi-sim functionality of Ecosim was used to simulate the dynamics of the groups from 2016 to 2098 for each of the future scenarios. Linear models were fitted to the log-transformed model outputs for the period 2016-2098 to investigate how the environmental, $F_{\text {cod }}$ and seal abundance scenarios affect the mean annual biomass, catches, seal consumption and fish predation mortality by seals of adult cod, herring and sprat in each scenario combination (Fig. S4). No carrying capacity limits were set for any of the functional groups.

\section{Mixed Trophic Impact (MTI)}

Ecopath uses the Network Analysis routine called Mixed Trophic Impact (MTI) to estimate the direct and indirect effects (positive or negative) that a change in the biomass of one functional group might have on another group's biomass (Appendix S3). To obtain the MTI for all modelled years (1974-2098), we used the 'Ecopath model from
Ecosim' tool. This tool generates a new Ecopath model for each of the years projected in Ecosim. We present here the effect (measured by MTI) of the adult seal group and of the cod trawl fishery on the fish, adult seal and fisheries groups in the Env $1+$ seal50 $+F_{\text {cod }}=0.3$ scenario combination. The Env1 scenario was selected for the MTI analysis as this was an 'intermediate' scenario in terms of environmental impacts. The seal biomass and cod fishing mortality scenarios seal50 and $F_{\text {cod }}=0.3$ were chosen because we wanted to assess the cod mortality under the strongest possible impact of seals while keeping $F_{\text {cod }}$ within the former European Union Council recovery plan (EC 2007).

In addition, given the relatively high proportion of prey outside the system in our model, we tested whether the MTI of seals on the prey would be different when eliminating the 'import' diet for seals and redistributing those values proportionally into the different prey groups. We tested this in the year 2094 and at seal50 to make sure seal abundance was at or near its potential peak.

\section{RESULTS}

\section{Model calibration and validation}

Our Ecopath model followed PREBAL ecological rules of thumb as described by Link (2010) (Fig. S5). Among all vulnerability multipliers, those that regulated the interactions of cod with its prey influenced model fit the most. The best fit for seal biomass was obtained when increasing the seals Switching Power to 2 and their prey vulnerability multipliers to $\gg 2$ (Appendix S2). Therefore, we assumed high vulnerability for the seal prey groups (i.e. juvenile and adult sprat, juvenile and adult herring, and juvenile, small and adult cod).

Grey seal diet projections for the years 1974, 2004 and 2010 were relatively similar to the empirical data for the periods 1968-1971, 2001-2005 and 2008-2012, respectively (Fig. 2). In the period 1968-1971, cod was a very important part of the diet for both juvenile and adult seals (21\%) and herring was of particular relevance in the juvenile seal diet (26\%), while sprat was of relative little importance compared to the other periods, both in our model (1974) and in the empirical data. During the other periods (2001-2005 and 2008-2012), both the model and the empirical data coincided in a major contribution of herring in the diet of seals. Other prey (e.g. salmon, eel, perch, flatfish, whitefish) were generally more important than cod, sprat or herring in the seal diet according to both the model and the observations in the first period (Fig. 2). In general, cod seemed to be more important in the diet of seals according to the model results than according to the empirical data (Fig. 2). 
Table 2 Description of scenarios used in the projections (2016-2098) in the food-web EwE model. Fishing mortalities of sprat and herring were kept constant during the scenarios at their respective 2015 levels (i.e. $F_{\text {herring }}=0.11$ and $F_{\text {sprat }}=0.21$ ). The environmental scenarios were named Env0, Env1 and Env2, indicating increasing anthropogenic pressures on the Baltic Sea

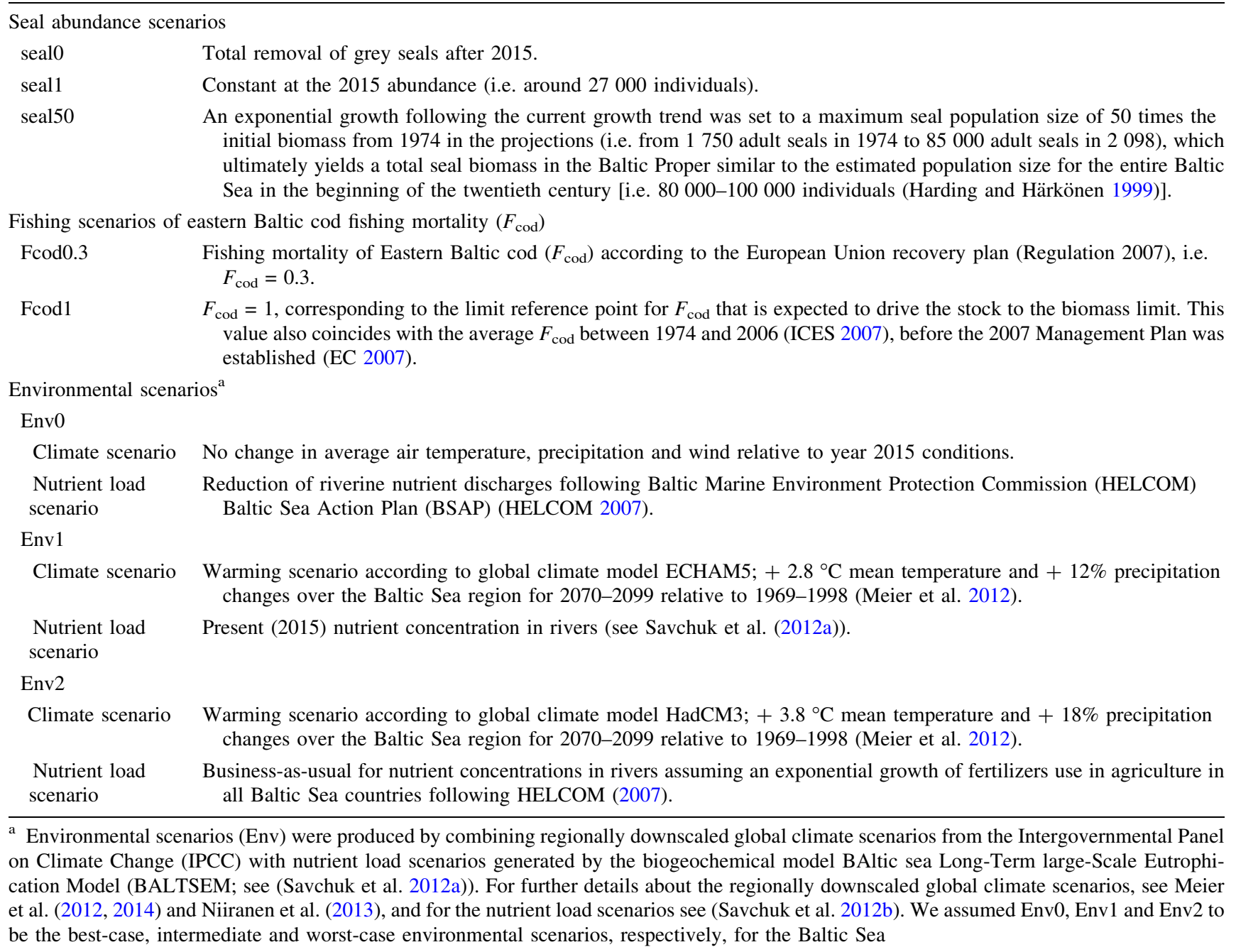

\section{Scenario simulations}

Under the seal50 scenario, the grey seal biomass was set to grow exponentially a peak of about $\sim 141000$ individuals, including both juvenile (56 640 individuals) and adult (84 840 individuals) seals, and then the seal biomass was forced to level off after the year 2039 .

\section{Adult fish biomass}

The projections time series from 1974 to 2098 show that adult and small cod biomasses under the Env0 scenario remain rather stable from 2015 regardless of $F_{\text {cod }}$ and of seal abundance (Fig. 3a). At Env1 and at Env2, and under $F_{\text {cod }}=0.3$, adult and small cod biomasses increase constantly over time under both seal0 and seal50 scenarios, with a steeper slope at Env1 than at Env2 (Fig. 3a). Overall, adult cod biomass was between 1.9 and 7.9 times lower under $F_{\text {cod }}=1$ than under $F_{\text {cod }}=0.3$ (Table S5). When $F_{\text {cod }}=0.3$, adult cod biomass was $13 \%$ lower under seal50 than under seal0, whereas when $F_{\text {cod }}=1$ cod biomass was less than $6 \%$ lower under seal50 than under seal0 (Table S5). Differences in adult cod biomass between $F_{\text {cod }}=0.3$ and $F_{\text {cod }}=1$ were significant $(p<0.05)$ in all environment scenarios. At $F_{\text {cod }}=0.3$, regardless of the seal abundance, the Env1 and Env2 environmental scenarios yielded higher adult cod, herring and sprat biomass than the Env0 scenario (Fig. S6A). At $F_{\text {cod }}=1$, regardless of the seal abundance, cod biomass reached the highest values in the Env1 scenario and the lowest values in the Env2 scenario, whereas herring and sprat biomass followed the same pattern as under $F_{\text {cod }}=0.3$ (Fig. S6A).

The adult and juvenile herring biomasses in Env0 scenario remain stable from 2015 to 2098 regardless of $F_{\text {cod }}$ and of seal abundance (Fig. 3b). At Env1 and at Env2, herring biomass increases constantly over time under both 

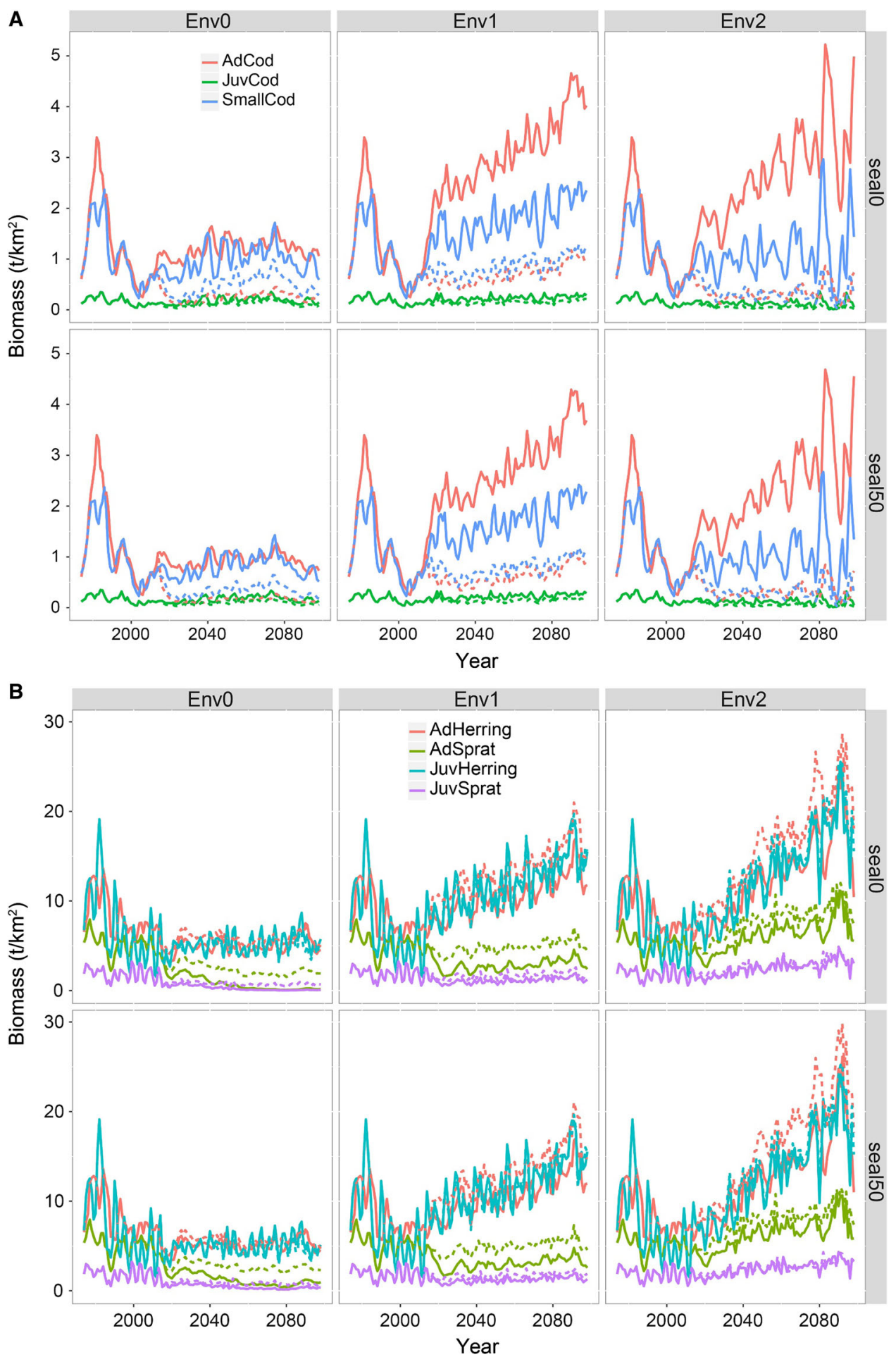

Fig. 3 Cod (a), and herring and sprat (b) biomasses from 1974 to 2098 under different environmental (columns: Env0, Env1 and Env2), seal abundances (rows: seal 0 and seal50) and cod fishing mortality ( $F_{\text {cod }} 0.3$ as continuous lines and $F_{\text {cod }} 1$ as dotted lines) scenarios. AdCod adult cod, JuvCod juvenile cod, SmallCod small cod, AdHerring adult herring, AdSprat adult sprat, JuvHerring juvenile herring, JuvSprat juvenile sprat

seal0 and seal50 scenarios, but with a steeper slope at Env2 than at Env1 (Fig. 3b). Adult herring biomass was 13-23\% lower under $F_{\text {cod }}=0.3$ than under $F_{\text {cod }}=1$ (Table S5), with significant differences between environment scenarios (e.g. around 2.6 higher under Env2 than under Env0) and between $F_{\text {cod }}$ scenarios, but not between seal scenarios (Table S5, Fig. S6A). 


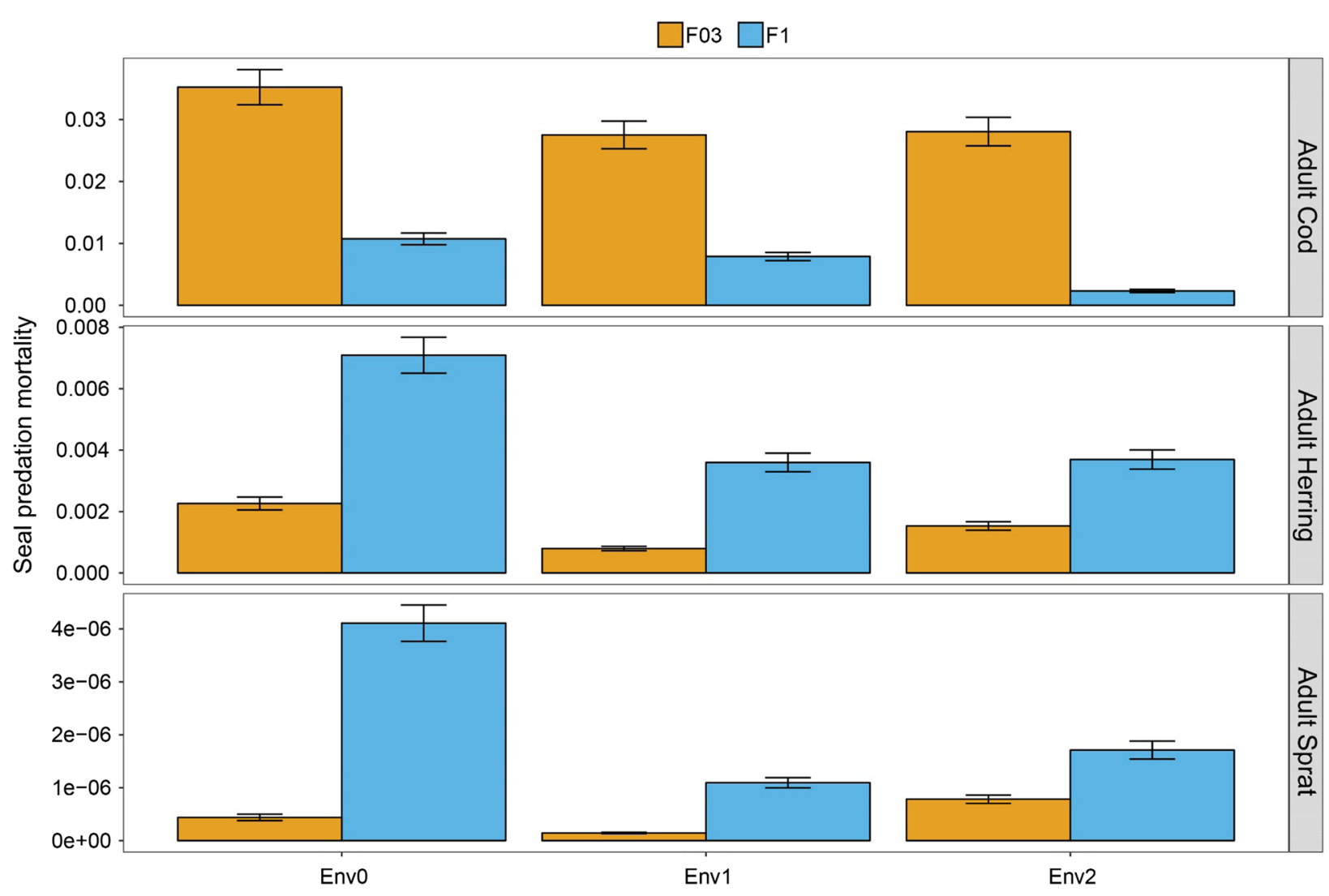

Fig. 4 Predation mortality by seals of adult cod, herring and sprat under environmental scenario combinations of Env0, Env1 and Env2 and cod fishing mortality scenarios $F_{\text {cod }}=0.3$ (orange) and $F_{\text {cod }}=1$ (blue) for the period 2015-2098. Only the seal50 scenario is represented here, as predation mortality of these prey at seall was near 0

The adult and juvenile sprat biomasses in Env0 scenario decrease slightly during the simulated period regardless of $F_{\text {cod }}$ and of seal abundance (Fig. 3b). At Env1 and at Env2, sprat biomass increases constantly over time under both seal0 and seal50 scenarios, but with a steeper slope at Env2 than at Env1 (Fig. 3b). The highest sprat biomass of all environmental scenarios was found under Env2, and the lowest biomass under Env0 (Table S5, Fig. S6A): in Env2 sprat biomass was 5,7 or 8 times higher than in Env0, under seal50, seal1 and seal0, respectively, when $F_{\text {cod }}=$ 0.3 . However, under $F_{\text {cod }}=1$ sprat biomasses were consistently higher than under $F_{\text {cod }}=0.3$ and the differences in sprat biomass between Env scenarios were smaller (Table S5), suggesting that there is an important indirect effect of $F_{\text {cod }}$ on sprat biomass.

\section{Seal consumption $(Q)$}

Juvenile and adult seal consumption (Q) of adult cod was between 16 and 93 times higher under $F_{\text {cod }}=0.3$ than under $F_{\text {cod }}=1$, depending on the environmental and seal abundance scenarios $\left(\mathrm{Q}\right.$ of cod was nearly 0 when $F_{\text {cod }}=$ $1)$. When $F_{\text {cod }}=0.3, \mathrm{Q}$ of cod was significantly lower under seal1 than under seal50, and it was $\sim 50 \%$ lower in the Env0 scenario than in the other two environmental scenarios (Table S6).

Seal consumption of adult herring was approximately 3 times higher when $F_{\text {cod }}=1$ compared to $F_{\text {cod }}=0.3$. Under $F_{\text {cod }}=0.3$, Q of herring was significantly higher at seal50. Overall, Q of herring was 1.5-2 higher in the Env2 scenario than in the other two environment scenarios (Table S6). Under $F_{\text {cod }}=1$, Q of sprat was generally 2-3 higher in the Env2 scenario than in the other two environment scenarios for both seall and seal50 scenarios, whereas under $F_{\text {cod }}=0.3$ the difference in sprat biomass between Env2 and the other environmental scenarios was more than double than under $F_{\text {cod }}=1$ (Fig. S6B) (Table S5).

\section{Adult fish catch}

Adult cod catches were between 1.3 and 2.4 times higher under $F_{\text {cod }}=0.3$ than under $F_{\text {cod }}=1$. Cod catches were significantly different between environment scenarios (Env1 > Env2 $>$ Env0), with higher differences when $F_{\text {cod }}=0.3$ than when $F_{\text {cod }}=1$. Adult herring and adult 


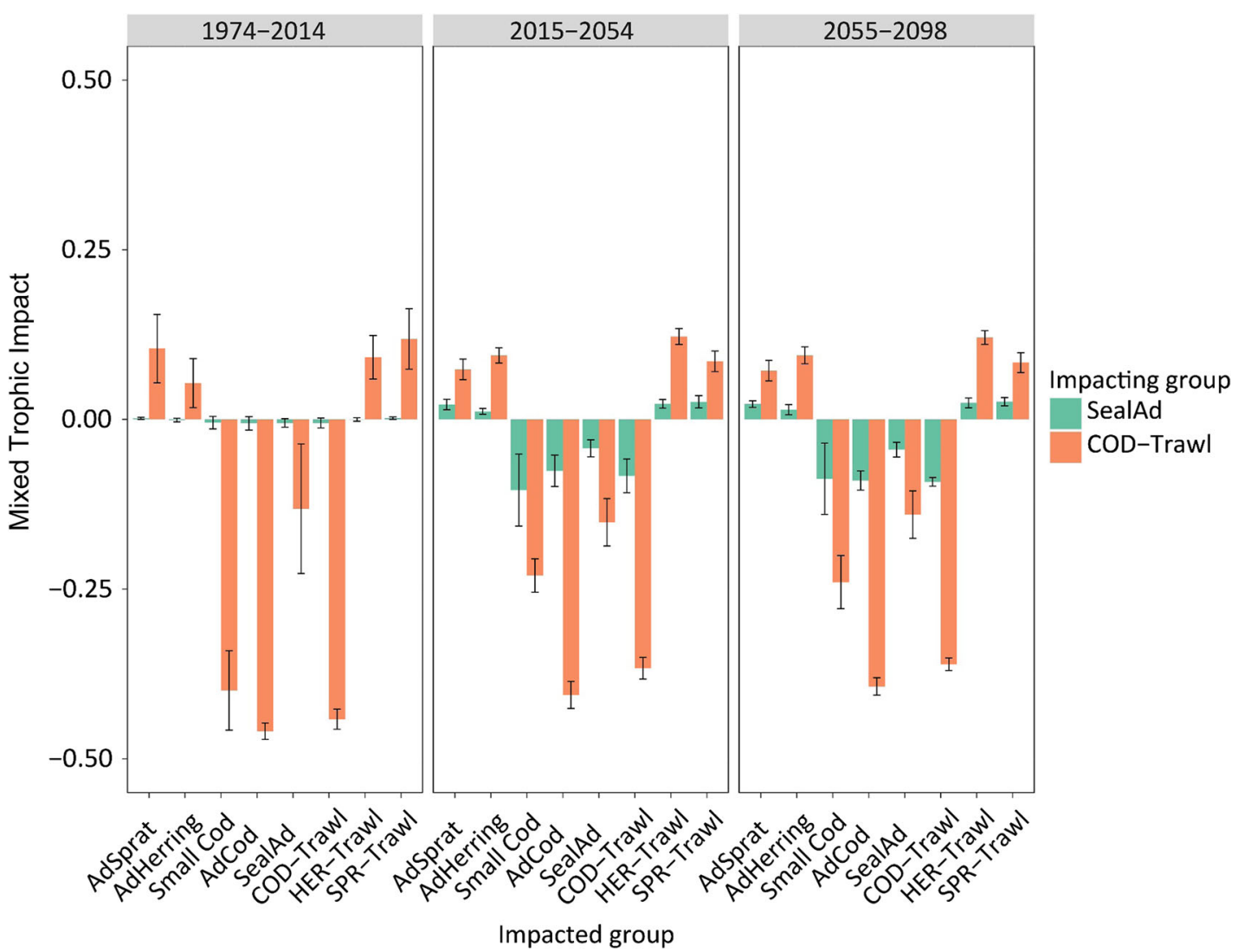

Fig. 5 Mixed Trophic Impact (MTI) by adult seals (SealAd) and cod fishery (COD-Trawl) on the small cod, the adult fish groups and seals and on the cod, herring (HER-Trawl) and sprat (SPR-Trawl) fisheries. AdHerring adult herring, AdSprat adult sprat, AdCod adult cod, SealAd adult seal

sprat catches followed patterns similar to the ones described above for their biomasses (Fig. S6C, Table S7). At seal50 and $F_{\text {cod }}=0.3$, Q of adult cod was $50-80 \%$ higher than adult cod catches (Tables S6 and S7).

\section{Predation mortality}

Predation mortality of adult cod by seals was significantly higher $(p<0.05)$ under $F_{\text {cod }}=0.3$ than under $F_{\text {cod }}=1$. Within both $F_{\text {cod }}$ scenarios, the predation mortality of adult cod by seals was higher under the Env0 scenario than under the other two environment scenarios (Fig. 4). For both herring and sprat, predation mortality by seals was also significantly higher under Env0, but, in opposition to cod, a much higher predation mortality by seals occurred when $F_{\text {cod }}=1$ (Fig. 4). Only when $F_{\text {cod }}=0.3$ and seal50, the consumption of adult cod by seal was larger than the catches.

\section{Mixed Trophic Impact}

The MTI of adult grey seal and cod fishery showed that both seals and the fishery have an overall negative impact on cod biomass $\left(\mathrm{MTI}_{\text {seal }}=-0.06, \quad \mathrm{MTI}_{\text {codFishery }}=\right.$
$-0.35)$ and on themselves $\left(\mathrm{MTI}_{\text {seal }}=-0.03, \mathrm{MTI}_{\text {codFishery }}\right.$ $=-0.06, \quad$ and $\quad \operatorname{MTI}_{\text {seal }}=-0.14, \quad \operatorname{MTI}_{\text {codFishery }}=$ -0.39 , by adult seal and cod fishery, respectively). From 1974-2014 to 2015-2054, the MTI of seals became more negative on cod, cod fishery and adult seal, but increased on the other fish species and fisheries. Cod fishery had an overall less negative impact during 2015-2098 than during 1974-2014, whereas the MTI of cod fishery on the other groups remained relatively unchanged over the entire time period. The MTI of adult seal and cod fishery do not vary between the 2015-2054 and 2055-2098 time periods (Fig. 5).

\section{DISCUSSION}

Our results showed that environment and fisheries scenarios influenced seal predation impacts on fish. Fish biomass and catches are more affected by fishing mortality and the environment than by seal predation. Therefore, this study reveals that the relationships between seal population, fish catches and fish biomass are more complex than previously stated (Wickens 1995; Trzcinski et al. 2006). Even with the 
relatively high adult seal consumption values used in our model $\left(6.9 \mathrm{~kg} \mathrm{day}^{-1}\right)$ compared to previous studies (e.g. $4.3 \mathrm{~kg} \mathrm{day}^{-1}$ and $3.2 \mathrm{~kg} \mathrm{day}^{-1}$ (Innes et al. 1987 and Elmgren 1989, respectively)), seal abundance generally did not have substantial effects on the adult fish biomasses.

The little impact of seals on fish populations shown by our study may seem counterintuitive. However, simple energetic calculations support our results. Given consumption rates of $2.52 \mathrm{t}$ fish/adult seal and $2.19 \mathrm{t}$ fish/juvenile seal per year, we calculated that a total of 100000 seals in the study area $\left(240000 \mathrm{~km}^{2}\right.$ ) would consume 238600 tons of fish per year. The model output for the seal diet composition in the period 2008-2012 showed that herring composed $\sim 41 \%$ of the diet for both juvenile and adult seals. Thus, seals consume 97800 tons of herring per year. Based on otolith sizes, it was estimated that approximately $50 \%$ of the herring identified in the digestive tract of grey seals were adult fish consumed in the Baltic Proper (see Lundström et al. 2007 for prey size estimations). Thus, 100000 seals would consume $\sim 49000$ tons of adult herring. This indicates that our simulation estimates of seal consumption are similar to empirical studies (Lundström 2012).

The spawning stock biomass (SSB) for herring was estimated 1341625 tons in ICES subdivisions 25-29 and 32 (excluding Gulf of Riga) in 2017 (ICES 2017a); therefore, the 49000 tons of adult herring consumed by the seals represent $3.65 \%$ of the estimated herring stock size in 2017. According to our model, at the end of the simulated period (year 2098) in the Env0, Fcod0.3 and seal50 scenarios (which is the combination of scenarios yielding the lowest biomass of adult herring in 2098) adult herring biomass would be $9.15 \%$ higher than in the year 2017 (juvenile herring biomass would be $20.65 \%$ higher in 2098 than in 2017). This suggests that $\sim 100000$ seals would be eating $3.34 \%$ of herring SSB at the end of the twenty first century. Also, predation mortality of herring (and sprat) is particularly low in the Fcod0.3 scenario in comparison to the Fcod1 scenario. This is likely because whenever cod is available (which would be the case if Fcod is low), grey seals tend to prey more on cod than on other species, as suggested by the fact that cod was as common as herring in the seal stomachs during the period 1968-1971, when both cod and herring stocks were larger than during 1974-2098 (also see Lundström et al. 2007). In the same way, in the Bothnian Sea, where grey seals have also increased in number and are the main predator for herring, this marine mammal consumes $6-12 \%$ of the total herring removal annually (Gårdmark et al. 2012).

Environmental forcing and cod fishing mortality $\left(F_{\text {cod }}\right)$ impacted the fish biomass substantially. Similarly, MacKenzie et al. (2011) showed that grey seal predation had a lower impact on cod recovery than other factors such as salinity and fishing. Concurrently, we showed that the effect of seal abundance on fish biomass, catches and predation mortality (as Q of adult fish) is greatly modulated by the environment and the cod fishing pressure, which indicates that the Baltic Sea is very environmentally driven and, at the same time, highly sensitive to anthropogenic impacts.

The combination of $F_{\text {cod }}=1$ and the Env2 scenarios yielded the lowest cod biomass of all the analysed future scenarios, regardless of the seal abundance. Similarly, Niiranen et al. (2013) described that under a Env2-like scenario combined with $F_{\text {cod }}=1.1$, cod presented the lowest biomass, whereas clupeid biomasses were higher. This means that there might be a synergistic negative interaction between high nutrient and high-temperature values (Env2) in combination with a high $F_{\text {cod }}$ affecting cod biomass growth. However, we found that the overall fish biomass under the Env0 scenario, particularly when $F_{\text {cod }}=0.3$, was the lowest. This is probably due to decreased primary production as a result of decreased nutrient inputs to the Baltic Sea assumed in Env0, which offsets the positive effects of decreased hypoxia (Fig. S2). However, we note that our model may overestimate the positive effects of a high primary production in Env1 and Env2, as under eutrophic conditions, especially when combined with high temperatures, the primary producer community may shift towards unfavorable species for consumers (Lehtiniemi et al. 2002; Neumann et al. 2012; Suikkanen et al. 2013).

The significantly higher MTI of seals on cod compared to the impact by cod fisheries indicated that the major driver of cod biomass in the Baltic Sea is the fishery. Similarly, Eero et al. (2015) documented that among fishing mortality, nutrient concentration, climate-driven hydrographic conditions and seal abundance, the latter was the only factor that did not have detrimental effects on the Eastern Baltic cod spawning stock biomass. Moreover, the negative MTI of cod fishery on the adult seal group due to removal of the seals' prey could lead to a deleterious effect on the Baltic seal populations, especially given the current situation of decreasing seal health condition (HELCOM 2017), which can be interpreted as an early signal of density dependence (Harding et al. 2018). Even though food limitation of seals is not plausible at current fish and seal population sizes, the lack of cod may affect seal populations in the future. It is also worth mentioning that the positive MTI values of the adult seal group on adult sprat and herring during the simulated period is likely linked to the impact that seals have on cod, which are in turn the main predators for herring and sprat, suggesting a trophic cascade effect. Our results also showed that predation mortality of Baltic fish by grey seals was higher in the Env0 scenario, in which cod, sprat and herring abundances had their lowest values. Thus, maintaining cod 
populations at relatively high abundance levels could reduce cod predation mortality by seals (e.g., Hammill et al. (2014)). Interestingly, the differences in seal diet composition between the datasets used in our model showed a decrease in the consumption of larger prey like cod and an increase in smaller prey (e.g. herring). This suggests a decrease in the trophic level of the seal diet, which coincides with the findings by Hanson et al. (2017) using stable isotopes of grey seals in the North Sea.

Our simulations have certain limitations as the model is a simplification of the food web in the open waters of the Baltic Proper (for further details see also Appendix S4). For example, changes in $F_{\text {herring }}$ and $F_{\text {sprat }}$ could have been defined, but at the expenses of further complexity to the study and a significantly larger amount of simulations. This subject is worthy of further study, as disproportionately decreasing $\mathrm{F}$ of herring or sprat compared to the other species could increase their populations and, consequently, their role in the diet of seals. Also, the model lacks some of the components of the system that are economically important in some areas of the Baltic Sea, such as sea trout, whitefish, flatfish, eels and perch, among others. We found that a more negative MTI of seals on their modelled prey could be expected if seal consumed exclusively herring, sprat and cod within the studied system (i.e. redistributing all the 'import' diet proportionally into the modelled prey) (Fig. S7), suggesting that it might be worth including coastal fish stocks in future models. Hansson et al. (2017) showed that seals might have a significant impact on some coastal fish populations, although the authors acknowledged that the proportions of near-shore fish species in the seals' diet might have been overestimated, as these diet samples are generally collected in coastal areas. If we consider the same bias in our study, our projections under the extreme seal50 scenario suggest that a higher proportion of more offshore species such as cod, herring and sprat in the seals' diet is still unlikely to have a significant impact on the offshore fish stocks. A spatially explicit model of seal-fishery interactions would be needed to more thoroughly investigate the impacts of seals on both coastal and offshore fish populations. A spatially explicit model would allow an explicit modelling of seal biomass development dependent on their interactions with both coastal and offshore fish species and fisheries. In addition, including the coastal perspective in the model could facilitate the assessment of the operational impacts that seals have on small-scale fisheries (Varjopuro 2011).

Most of the operational interactions between seals and fisheries take place in coastal areas. Given the ecological and oceanographic differences between the open sea and the coastal areas, our model does not allow to extrapolate our results in order to elucidate the ecological effects of seals on Baltic coastal fisheries such as salmon, eel or whitefish. Nevertheless, the operational conflicts between seals and coastal fisheries should be managed following an approach that can both secure the revenues of the fishers and guarantee the conservation and good status of the grey seal population in the Baltic Sea. As an example, in Sweden some studies have shown the efficacy of new sealproof fishing traps in the Baltic (Königson 2011).

\section{CONCLUSIONS}

This work shows that the impacts of the increasing Baltic grey seal population on fish stocks are complex. We emphasize the need to consider a range of possible ecosystem contexts when evaluating potential impacts of top predators. Our results provide evidence that consumption by grey seals at a population size of $\sim 30000$ individuals affects fish biomass in the offshore Baltic Proper significantly less than climate change, nutrient load and fisheries. Responses of fisheries stakeholders to a further increase in the seal population are not easy to foresee but negative responses among some fisheries collectives can be anticipated. However, we suggest that an increasing seal population is not likely to hinder the preservation of the main Baltic fish stocks, and we expect that the outcomes of our study will help to shed light on the controversy.

Conflicts and competition for fisheries resources between humans and marine predators are difficult to quantify, and are therefore challenging to manage. Our study can serve as a guide for more holistic approaches to management and conservation advice. When managing fisheries, it is necessary to consider not only the state of the fish stocks but also the environmental conditions and the biology of the fish predators, as well as the fisheries response to these factors, in an integrative way. Moreover, the management and conservation of seals need to be strategic and based on long-term plans.

Acknowledgements This is a contribution to the BONUS BIO-C3 project and was supported by BONUS (Art 185), funded jointly by the EU and the Swedish Research Council FORMAS. BB received funding from MareFrame project (Co-creating Ecosystem-based Fisheries Management Solutions)_EU 7th FP under Grant agreement no. 613571 .

Open Access This article is distributed under the terms of the Creative Commons Attribution 4.0 International License (http:// creativecommons.org/licenses/by/4.0/), which permits unrestricted use, distribution, and reproduction in any medium, provided you give appropriate credit to the original author(s) and the source, provide a link to the Creative Commons license, and indicate if changes were made. 


\section{REFERENCES}

Bogstad, B., H. Gjøsæter, T. Haug, and U. Lindstrøm. 2015. A review of the battle for food in the Barents Sea: cod vs. marine mammals. Frontiers in Ecology and Evolution 3: 29. https://doi. org/10.3389/fevo.2015.00029.

Casini, M., J. Lovgren, J. Hjelm, M. Cardinale, J.-C. Molinero, and G. Kornilovs. 2008. Multi-level trophic cascades in a heavily exploited open marine ecosystem. Proceedings of the Royal Society B: Biological Sciences 275: 1793-1801. https://doi.org/ 10.1098/rspb.2007.1752.

Chasco, B.E., I.C. Kaplan, A.C. Thomas, A. Acevedo-Gutiérrez, D.P. Noren, M.J. Ford, M.B. Hanson, J.J. Scordino, et al. 2017. Competing tradeoffs between increasing marine mammal predation and fisheries harvest of Chinook salmon. Scientific Reports 7: 15439. https://doi.org/10.1038/s41598-017-14984-8.

Christensen, V., and C.J. Walters. 2004. Ecopath with Ecosim: Methods, capabilities and limitations. Ecological Modelling 172: 109-139. https://doi.org/10.1016/j.ecolmodel.2003.09.003.

EC. 2007. Council Regulation(EC) no.1098/2007 establishing a multiannual plan for the cod stocks in the Baltic Sea and the fisheries exploiting those stocks, amending regulation (ECC)no. $2847 / 93$ and repealing regulation(EC)no. 779/97. Official Journal of the European Union, L. Vol. 248.

Eero, M. 2012. Reconstructing the population dynamics of sprat (Sprattus sprattus balticus) in the Baltic Sea in the 20th century. ICES Journal of Marine Science 69: 1010-1018.

Eero, M., J. Hjelm, J. Behrens, K. Buchmann, M. Cardinale, M. Casini, P. Gasyukov, N.N. Holmgren, et al. 2015. Eastern Baltic cod in distress: biological changes and challenges for stock assessment. ICES Journal of Marine Science 72: 2180-2186. https://doi.org/10.1093/icesjms/fsv109.

Elmgren, R. 1989. Man's impact on the ecosystem of the Baltic Sea: energy flows today and at the turn of the century. Ambio 18: 326-332.

Elmgren, R., T. Blenckner, and A. Andersson. 2015. Baltic Sea management: Successes and failures. Ambio 44: 335-344. https://doi.org/10.1007/s13280-015-0653-9.

Furness, R.W. 2006. How many fish should we leave in the sea for seabirds and marine mammals? Top Predators in Marine Ecosystems 12: 211-222.

Gårdmark, A., Ö. Östman, A. Nielsen, K. Lundström, O. Karlsson, J. Pönni, and T. Aho. 2012. Does predation by grey seals (Halichoerus grypus) affect Bothnian Sea herring stock estimates? ICES Journal of Marine Science 69: 1448-1456. https:// doi.org/10.1093/icesjms/fss099.

Gårdmark, A., M. Casini, M. Huss, A. van Leeuwen, J. Hjelm, L. Persson, and A.M. de Roos. 2015. Regime shifts in exploited marine food webs: detecting mechanisms underlying alternative stable states using size-structured community dynamics theory. Philosophical Transactions of the Royal Society B: Biological Sciences. https://doi.org/10.1098/rstb.2013.0262.

Hammill, M.O., G.B. Stenson, D.P. Swain, and H.P. Benoît. 2014. Feeding by grey seals on endangered stocks of Atlantic cod and white hake 71: 1332-1341. https://doi.org/10.1093/icesjms/fsu123.

Hanson, N., E.L. Jones, and R.N. Harris. 2017. Multi-decadal and ontogenetic trophic shifts inferred from stable isotope ratios of pinniped teeth. Oikos. https://doi.org/10.1111/oik.04441.

Hansson, S., U. Bergström, E. Bonsdorff, T. Härkönen, N. Jepsen, L. Kautsky, K. Lundström, S.-G. Lunneryd, et al. 2017. Competition for the fish-fish extraction from the Baltic Sea by humans, aquatic mammals, and birds. ICES Journal of Marine Science 75: 999-1008.

Harding, K.C., and T.J. Härkönen. 1999. Development in the Baltic Grey Seal (Halichoerus grypus) and Ringed Seal (Phoca hispida) populations during the 20th Century. Ambio 28: 619-627.
Harding, K.C., M. Salmon, J. Teilmann, R. Dietz, and T. Harkonen. 2018. Population wide decline in somatic growth in Harbor Seals: Early signs of density dependence. Frontiers in Ecology and Evolution 6: 59. https://doi.org/10.3389/fevo.2018.00059.

Härkönen, T., A. Galatius, S. Bräger, O. Karlsson, and M. Ahola. 2013. Population growth rate, abundance and distribution of marine mammals. HELCOM Core Indicator of Biodiversity $1-34$.

Heikinheimo, O., P. Rusanen, and K. Korhonen. 2016. Estimating the mortality caused by great cormorant predation on fish stocks: pikeperch in the Archipelago Sea, northern Baltic Sea, as an example. Edited by Marie-Joëlle Rochet. Canadian Journal of Fisheries and Aquatic Sciences 73: 84-93. https://doi.org/10. 1139/cjfas-2015-0033.

HELCOM. 2007. Baltic Sea Action Plan. HELCOM Ministerial Meeting. Krakow, Poland, 15 Nov 2007. http://www.helcom.fi/ BSAP/ActionPlan/en_GB/ActionPlan.

HELCOM. 2017. 'Population trends and abundance of seals'updated core indicator report. Uppsala: HELCOM.

ICES. 2007. ICES WGBFAS Report 2007. Report of the Baltic Fisheries Assessment Working Group (WGBFAS). ICES CM 2007/ACFM:15. Copenhagen, Denmark.

ICES. 2017a. Report of the Baltic Fisheries Assessment Working Group (WGBFAS). Copenhagen, Denmark: ICES.

ICES. 2017b. Summary of ICES advice on the exploitation of Baltic Sea fish stocks in 2017, 1-22. Copenhagen, Denmark: ICES.

Innes, S., D.M. Lavigne, W.M. Earle, and K.M. Kovacs. 1987. Feeding Rates of Seals and Whales. J Animal Ecol 56: 115. https://doi.org/10.2307/4803.

Königson, S. 2011. Seals and fisheries: a study of the conflict and some possible solutions: 1-29.

Lehtiniemi, M., J. Engstrom-Ost, M. Karjalainen, B. KozlowskySuzuki, and M. Viitasalo. 2002. Fate of cyanobacterial toxins in the pelagic food web: transfer to copepods or to faecel pellets? Marine Ecology Progress Series 241: 13-21. https://doi.org/10. 2307/24866101.

Link, J.S. 2010. Adding rigor to ecological network models by evaluating a set of pre-balance diagnostics: A plea for PREBAL. Ecological Modelling 221: 1580-1591. https://doi.org/10.1016/j. ecolmodel.2010.03.012.

Lotze, H., M. Coll, A. Magera, C. Ward-Paige, and L. Airoldi. 2011. Recovery of marine animal populations and ecosystems. Trends in Ecology \& Evolution 26: 595-605. https://doi.org/10.1016/j. tree.2011.07.008.

Lundström, K. 2012. Assessment of dietary patterns and prey consumption of marine mammals Grey seals (Halichoerus grypus) in the Baltic Sea. Gothenburg: University of Gothenburg.

Lundström, K., O. Hjerne, K. Alexandersson, and O. Karlsson. 2007. Estimation of grey seal (Halichoerus grypus) diet composition in the Baltic Sea. NAMMCO Scientific Publications 6: 177-196.

Lundström, K., O. Hjerne, S.-G. Lunneryd, and O. Karlsson. 2010. Understanding the diet composition of marine mammals: grey seals (Halichoerus grypus) in the Baltic Sea. ICES Journal of Marine Science 67: 1230-1239. https://doi.org/10.1093/icesjms/ fsq022.

MacKenzie, B., M. Eero, and H. Ojaveer. 2011. Could Seals Prevent Cod Recovery in the Baltic Sea? PLoS ONE 6: e18998. https:// doi.org/10.1371/journal.pone.0018998.

MacKenzie, B., H. Meier, M. Lindegren, S. Neuenfeldt, M. Eero, T. Blenckner, M. Tomczak, and S. Niiranen. 2012. Impact of climate change on fish population dynamics in the Baltic Sea: A dynamical downscaling investigation. Ambio 41: 626-636. https://doi.org/10.1007/s13280-012-0325-y.

Magera, A., J. Flemming, K. Kaschner, L. Christensen, and H. Lotze. 2013. Recovery trends in marine mammal populations. PLoS ONE 8: e77908. https://doi.org/10.1371/journal.pone.0077908. 
Meier, H.E.M., H.C. Andersson, B. Arheimer, C. Donnelly, K. Eilola, B.G. Gustafsson, L. Kotwicki, T.S. Neset, et al. 2014. Ensemble modeling of the Baltic Sea ecosystem to provide scenarios for management. Ambio 43: 37-48. https://doi.org/10.1007/s13280013-0475-6.

Meier, H.E.M., R. Hordoir, H.C. Andersson, C. Dieterich, K. Eilola, B.G. Gustafsson, A. Höglund, and S. Schimanke. 2012. Modeling the combined impact of changing climate and changing nutrient loads on the Baltic Sea environment in an ensemble of transient simulations for 1961-2099. Climate Dynamics 39: 2421-2441.

Morissette, L., and P. Brodie. 2014. Assessing the trophic impacts of marine mammals: From metabolism to food web indices. Marine Mammal Sciences 30: 939-960. https://doi.org/10.1111/mms. 12118.

Neumann, T., K. Eilola, B. Gustafsson, B. Müller-Karulis, I. Kuznetsov, H.E.M. Meier, and O.P. Savchuk. 2012. Extremes of temperature, oxygen and blooms in the Baltic Sea in a changing climate. Ambio 41: 574-585. https://doi.org/10.1007/ s13280-012-0321-2.

Niiranen, S., J. Yletyinen, M. Tomczak, T. Blenckner, O. Hjerne, B. MacKenzie, B. Müller-Karulis, T. Neumann, et al. 2013. Combined effects of global climate change and regional ecosystem drivers on an exploited marine food web. Global Change Biology 19: 3327-3342. https://doi.org/10.1111/gcb. 12309.

O'Boyle, R., and M. Sinclair. 2012. Seal-cod interactions on the Eastern Scotian Shelf: Reconsideration of modelling assumptions. Fisheries Research 115: 1-13. https://doi.org/10.1016/j. fishres.2011.10.006.

Perrin, W.F., B.G. Würsig, and J.G.M. Thewissen. 2009. Encyclopedia of marine mammals. Amsterdam: Elsevier/Academic Press.

Raid, T., L. Järv, J. Pönni, J. Raitaniemi, and G. Kornilovs. 2016. Central Baltic herring stock: What does the assessment of combined stock say about the status of its components? In Maritime technology and engineering III: Proceedings of the $3 \mathrm{rd}$ international conference on maritime technology and engineering (MARTECH 2016, Lisbon, Portugal, 4-6 July 2016)/Eds. Carlos Guedes Soares and TA Santos. Taylor \& Francis Group.

Savchuk, O.P., B.G. Gustafsson, and B. Müller-Karulis. 2012a. BALTSEM: A marine model for decision support within the Baltic Sea Region. Baltic Nest Institute Technical Report, 7, p. 55.

Savchuk, O.P., B.G. Gustafsson, M.R. Medina, A.V. Sokolov, and F.V. Wulff. 2012b. External nutrient loads to the Baltic Sea, 1970-2006. BNI Technical Report, 22.

Scott, E., N. Serpetti, J. Steenbeek, and J.J. Heymans. 2015. A stepwise fitting procedure for automated fitting of Ecopath with Ecosim models. SoftwareX 5: 25-30. https://doi.org/10.1016/j. softx.2016.02.002.

Söderberg, S. 1975. Feeding habits and commercial damage of seals in the Baltic. In Proceedings from the symposium on the seal in the Baltic, Lidingö, Sweden, June 4-6, 1974., SNV PM 591:66-78.

Suikkanen, S., S. Pulina, J. Engström-Öst, M. Lehtiniemi, S. Lehtinen, and A. Brutemark. 2013. Climate change and eutrophication induced shifts in northern summer plankton communities. PLOS ONE 8: e66475. https://doi.org/10.1371/ journal.pone.0066475.

Svedäng, H., and S. Hornborg. 2015. Waiting for a flourishing Baltic cod (Gadus morhua) fishery that never comes: Old truths and new perspectives. ICES Journal of Marine Science 72: 2197-2208.

Tomczak, M.T., S. Niiranen, O. Hjerne, and T. Blenckner. 2012. Ecosystem flow dynamics in the Baltic Proper-Using a multitrophic dataset as a basis for food-web modelling. Ecological Modelling 230: 123-147. https://doi.org/10.1016/j.ecolmodel. 2011.12.014.
Tomczak, M.T., J.J. Heymans, J. Yletyinen, S. Niiranen, S.A. Otto, and T. Blenckner. 2013. Ecological network indicators of ecosystem status and change in the Baltic Sea. PLOS ONE 8: 1-11. https://doi.org/10.1371/journal.pone.0075439.

Trzcinski, M.K., R. Mohn, and W.D. Bowen. 2006. Continued decline of an Atlantic cod population: how important is gray seal predation? Ecological Applications: A Publication of the Ecological Society of America 16: 2276-2292.

Varjopuro, R. 2011. Co-existence of seals and fisheries? Adaptation of a coastal fishery for recovery of the Baltic grey seal. Marine Policy 35: 450-456. https://doi.org/10.1016/j.marpol.2010.10. 023.

Walters, C., V. Christensen, W. Walters, and K. Rose. 2010. Representation of Multistanza Life Histories in Ecospace Models for Spatial Organization. Bulletin of Marine Science 86: 439-459.

Wickens, P. A. 1995. A review of operational interactions between pinnipeds and fisheries. FAO Fisheries Technical Paper (FAO).

Yodzis, P. 2001. Must top predators be culled for the sake of fisheries? Trends in Ecology \& Evolution 16: 78-84.

\section{AUTHOR BIOGRAPHIES}

David Costalago $(\square)$ is a postdoctoral Mitacs fellow at the Institute for Oceans and Fisheries at the University of British Columbia. His main research interests include pelagic food-web dynamics, fisheries ecology and ecosystem modelling.

Address: Department of Ecology, Environment and Plant Sciences, Stockholm University, Campus Frescati, Svante Arrhenius väg $20 \mathrm{~F}$, 10691 Stockholm, Sweden.

Address: Institute for the Oceans and Fisheries, University of British Columbia, UBC-AERL, 2202 Main Mall, Vancouver, BC V6T 1Z4, Canada.

e-mail: nauplius97@gmail.com

Barbara Bauer is a postdoctoral researcher at the Baltic Sea Centre, Stockholm University. Her research interests include food-web ecology, spatial modelling and socio-ecological systems.

Address: Baltic Sea Centre, Stockholm University, Campus Frescati, Svante Arrhenius väg 20 F, 10691 Stockholm, Sweden. e-mail: Barbara.bauer@su.se

Maciej T. Tomczak is a researcher at the Baltic Sea Centre, Stockholm University. His research interests include changes in marine food webs using different modelling tools and ecosystem-based fisheries management.

Address: Baltic Sea Centre, Stockholm University, Campus Frescati, Svante Arrhenius väg 20 F, 10691 Stockholm, Sweden.

e-mail: maciej.tomczak@su.se

Karl Lundström is a researcher at the Department of Aquatic Resources at the Swedish University of Agricultural Sciences (SLU). His research interests include ecology of aquatic top predators.

Address: Department of Aquatic Resources, Swedish University of Agricultural Sciences (SLU), Turistgatan 5, 45330 Lysekil, Sweden. e-mail: karl.lundstrom@slu.se

Monika Winder is a professor in marine ecology at Stockholm University, Department of Ecology, Environment and Plant Sciences with particular interests in the causes and consequences of environmental change for food-web interactions and ecosystem functioning. Her research addresses questions in lakes, estuarine-coastal and ocean ecosystems with a special emphasis on planktonic organisms.

Address: Department of Ecology, Environment and Plant Sciences, Stockholm University, Campus Frescati, Svante Arrhenius väg 20 F, 10691 Stockholm, Sweden.

e-mail: monika.winder@su.se 